\title{
Dispatch
}

\section{Stopgaps, Beasts + Other Strategies of Being in Public Space}

\author{
LISA HIRMER \\ DodoLab, Canada \\ ELIZABETH JACKSON \\ University of Guelph, Canada
}

Editor's Note: the following is a dispatch from Elizabeth Jackson, Community Engagement Officer with the International Institute for Critical Studies in Improvisation at the University of Guelph, followed by a conversation between Jackson and artist Lisa Hirmer, Director of experimental arts practice DodoLab.

\section{Dispatch: Stopgaps and Gems}

During the cold and grey fall of 2014, a group of newcomer and immigrant youth, drawn together by our community partner Immigrant Services Guelph Wellington, gathered at the public library in downtown Guelph. They were taking part in a youth leadership program, and I had worked with the International Institute for Critical Studies in Innovation's (IICSI) community research partners Immigrant Services - Guelph Wellington and creative arts practice DodoLab, to integrate a series of arts-based workshops into the program. I had the pleasure of working with DodoLab's director, Lisa Hirmer - an artist, arts-based researcher, IICSI community partner, and all around lovely human - to support and co-facilitate the series of arts workshops exploring the youths' experiences of what I think of as "mundane improvisation" or improvisation in daily life, their reactions to unanticipated challenges and circumstances. We started with a story circle format where youth shared their tales of unexpected challenges or surprising experiences, and how they had responded to and navigated them. As teenagers, as newcomers to a culture that was in most cases very different than their home 
cultures, and as people who had carried out long-distance emigrations, often alone, these kids had amazing stories to tell. Some of them were funny, some of them were silly, some of them were devastating, some of them were very profound. All of them mattered. In later workshops, with Lisa's excellent facilitation, the youth worked with clay, and beads, and pencils, and wire, and so on, to represent these stories, and what they'd learned from each other's stories, into small mementoes or trinkets that Lisa calls "shareables."

I like that word a lot, and particularly in the context of this project, because it sounds like parables. I like it a lot because in this context, in an engaged context, sharing is at the heart of our work and our process. Early on, the youth decided that this work could not stay inside our room in the library, and that they wanted to get outside and do something. We'd been hoping they'd want to carry out some kind of intervention, so this worked for us. They also insisted that there be balloons. So, at our last meeting, on a freezing cold November evening, Lisa arrived with dozens of shareables she'd had 3D printed based on the youths' prototypes, and with several enormous bunches of brightly coloured balloons.

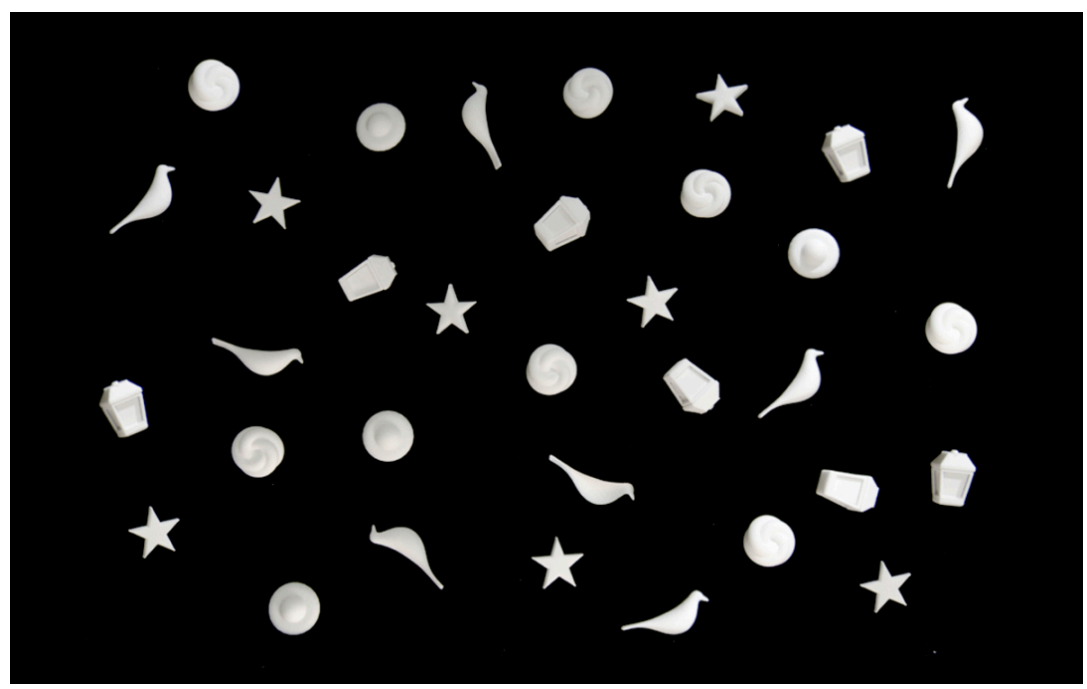

Figure 1: Shareables - Stopgaps and Gems (Photo: L. Hirmer); 3D printed "shareables" were distributed by youth participants during our public intervention.

We all looked at the shareables, did a little filing to smooth their edges, and talked about the stories and lessons they represented. Then we all bundled up and went outside, balloons trailing above us. Our small parade made its way to St. George's Square, a central point in Guelph - it's where all the banks have their main branches, and it's also a transit hub, so lots of bus routes start and end there. We were there around 5:00 or 5:30 p.m., peak commuting time on a weekday. 
And, at least to my eyes, something magical happened. These teenagers, some with hesitance and self-consciousness, others with flair and laughter, mustered up the courage to be vulnerable. Slowly, they began approaching strangers and asking if they'd like to hear a story. And I think everyone, every one of those rushing hungry homeward-bound people, said yes.

So stories were exchanged, and shareables were handed out, and a whole lot of people had maybe a baffling, maybe a wonderful, maybe a lifechanging, maybe a quite banal moment with someone who was a stranger to them. And then when the shareables were gone and we were seeped through with cold, we packed up and went back to the library, and then home.

From my perspective, as an arts-based and community engaged thinker, what I saw happen was an example of what George Lipsitz calls art-based community making. Lipsitz explains that he and his co-authors "argue that what critics and curators often describe as community-based art making is better described as art-based community making - a form of democratic interaction that enacts the just social relations that social movements often only envision" (Lipsitz, cited in Estrada, 2013).

What I saw happen was an erosion of the socially constructed walls that keep us away from one another; an assertion of belonging in a place and a public that, as we'd learned from the youths' stories, is often inhospitable. I saw a growth of confidence and community in the youth who had shared their stories with each other, and then I saw a shift in the relationships between these new members of Guelph's community and the many people who had, presumably, lived there much longer than they had, and who moved more freely and confidently through the square. I saw what can happen when stories are shared and trust is built. I saw the joy that a small surprise, a moment of human contact, can bring to someone as they go about their daily life.

I can't say, and it isn't mine to say, what those youth made of the workshops, and of the intervention, or what they make of it all now, should they think back on it. I can't tell you, and I don't know, what those people at St. George's Square made of those stories and encounters. We talked it over, back at the library, and what I can tell you is that one participant realized, and told us with quite some gravity, that this was the first time she had ever spoken English, in public, to a stranger.

And I don't know what that means, but I know that, when I think about it a certain way, it might be everything. 


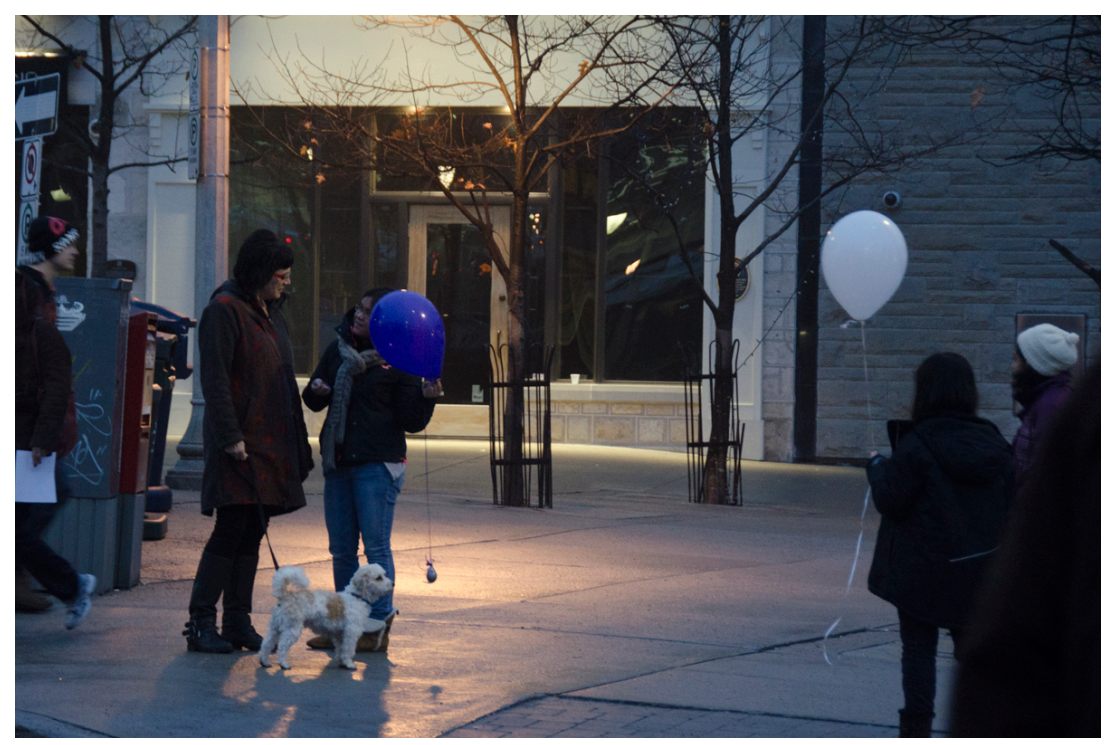

Figure 2: Rush hour sharing, Stopgaps and Gems (Photo: L. Hirmer); Youth speak with other members of the community.

\section{Dispatch in Dialogue}

Elizabeth Jackson (EJ): Lisa, over the time that we have known each other and worked together, we have talked a lot about our understandings of the impacts and potentialities of art with/in community (with "art" and "community" being defined in shifting and various ways across contexts, and with impacts never understood as fixed, pre-determined, or ever fully knowable). Drawing on your diverse experiences as a practitioner, and reflecting on our collaboration last year, can you talk about how you understand improvised and creative practices to resist the erosion of public spaces? What is at stake in these acts of resistance, and why are you committed to facilitating these interventions in the regulation of public spaces?

Lisa Hirmer (LH): DodoLab, in general, is focussed on revealing and interrupting barriers, moments where humans get stuck inside tangles of ideas and habits. The work is never only about something in and of itself. Instead it is about an idea or topic in relation to the public's understandings and beliefs about that idea or topic. This is because the way ideas move through the public realm is important. It is something we have to engage with. Though it's important to note that when I say public I actually mean a specific public, or counter-public or community. It's just a shorthand for some kind of 
collectivity, whatever that is in the moment of each project, and not a claiming of authority or erasing of difference.

EJ: Yes, there has to be room for disagreement and conflict in community.

LH: Exactly. The work of DodoLab isn't about consensus or clear research outcomes. It's about engaging as an artist with the messy, complicated, contradictory, amorphous realm of public ideas, acknowledging that the "realm of public ideas" is itself a messy, amorphous idea. It is important that the work isn't just about this, though; it is critical that it also happens in a public way. So both with the public and in public. It cannot be work that happens in isolation. It has to be activated by other voices and so is contingent on those other voices coming together. This means that DodoLab's projects have to create opportunities or mechanisms for meaningful exchange in the public sphere, which means they usually ends up triggering a temporary public life of a type we don't often experience in North American cities these days.

That said there are projects I've done that do engage more directly with public spaces and how those spaces are functioning. I see these projects as tiny interruptions, or maybe reminders is a better word? In any case, a small, temporary change in our usual ways of moving through and acting in public space that forces us to improvise different ways of being there - often which are actually always available to us but rarely enacted out of habit or subtle social pressures. I think this works better when the projects are unstable, when they aren't really sustainable past a brief moment in that particular time and place, with those particular participants. Somehow this open nature, you might even call it messiness, means the projects brush up against banal, daily human patterns in a way something more structured couldn't. There's a gap where people have to figure it out and decide how to engage with it and I think this is what fosters meaningful alternative interactions - maybe not ones that last but they are at least rehearsing another way of being in public.

EJ: So Dodolab's work conceives of public spaces both in physical terms and as an intellectual or dialogical space, a making room for ideas and exchanges. I've written about my impressions of Stopgaps and Gems - can you offer some more examples of projects you have created that do this kind of tinkering with public ideas, as you say, and that work to jangle with the selfevidences of what is normal or acceptable behaviour in a public space (in either sense)? Can you share some ways in which you have created moments of connection, or disrupted regulated normalcy, in human environments?

LH: Yes, Stopgaps and Gems, of course, which we can talk about, but first I want to talk about an early DodoLab project, The First Annual Tournament of Beasts, which happened in Sudbury with the youth at the Sudbury Action Centre for Youth (SACY). The First Annual Tournament of Beasts was a 
project about how public space is regulated and controlled. It was focussed on the experiences of young people at SACY, which is a drop-in centre in downtown Sudbury. It began quite simply with talking to them about their experiences of the city, about how they moved through and engaged with it. One exercise was giving them cameras to go take photos of things they found significant about the downtown. Multiple participants came back with photographs of signs stating what couldn't happen in those spaces (no loitering, no bikes, etc.), and especially many photos of one sign that was posted at each of the entrances of a large downtown park listing the things that weren't permitted there. The project actually started as a joke, because one part of the sign read something like "no dogs, cats, drinking or golfing," so we laughed about inebriated, golf-playing canines and felines causing these items to get specifically listed. But more seriously it was a symptom of a strategy of limitation and restriction in the city's downtown core.

So the project was a playful poke at that idea. The youth dressed as animals (a raccoon, a wolf, a moose, etc., but no cats or dogs) and spent the afternoon playing croquet (not golf) in that park. The project was about creating a positive and playful way to disrupt patterns of thinking that seemed to have gotten rather confrontational. It was also about creating a moment of permission for the youth to occupy a space, creating a really tangible way to imagine how things could be different. It also posed a question to the public (as well as police officers and local government) about whether encouraging active use and vibrant public life isn't perhaps a much better way to create good urban spaces.

EJ: Can you talk a bit about how participants and passersby reacted to it? How did others read this intervention?

LH: Well, even if no one had seen this intervention, it would have still been about access and a kind of permission that can be created through creative work. The performance of the tournament became a buffer that allowed these kids to just be kids having fun in a park for an afternoon without suspicion, without antagonism. I do think it was significant for people to see that though, a reintroduction of this space and the youth to each other. And passersby reacted quite positively to it. It isn't just the youth affected by these regulations. One older woman recalled that she had been kicked out of the park for reading a book on the grass for too long. When the tone is to control by limiting then it's not surprising that the park is often empty. This isn't to gloss over the very real issues with substance abuse in the park but rather about resetting the tone of conversations around this, which didn't seem to be working for anyone. Activity begets more activity. I do think Sudbury has changed a lot since this project took place. There are many larger factors that went into this, but I would like to think this project was a drop or two in that bucket. 
EJ: Can we talk about cities for a second? What is it about cities in particular that you wanted to attend to? Is it because there are lots of people in close proximity to one another? Or having particular relationships with each other and their space? Is it about the "ownership" of supposedly public spaces?

LH: Good question. To be fair, in both these cases the urban context was set by the circumstances of the projects' origins. But yes, I think the density of people matters, which isn't to say that interventions can't be effective in less dense areas, but they would take on a different tone. Cities have a density of different experiences, which is to say, people navigating the city in very different ways, but habits or efficiencies mean these experiences only meet at certain nodes, often defined by commercial activity. To me there seems to be a richness of potential interactions, near interactions we could call them, that could be triggered by creative work.

EJ: I had such a blast participating in the Stopgaps and Gems workshops and the final outing or intervention. I observed so many of these moments you're talking about, so many small pauses in people's habituated routines and ways of interacting - or, more accurately, not interacting - in the downtown space. Some of these interactions were quick and cheery, and others were more prolonged and quite moving. Can you talk some more about how that project began, and how it unfolded? I' $m$ really interested in the process that led to the final intervention.

LH: Stopgaps and Gems was a project working with a group of newcomer youth. Not unlike the Tournament of Beasts project it began with group conversations though this time it took on more of a storytelling tone. The youth shared stories about unexpected moments of things going wrong and how they worked their way out of the situation - stories like getting on the wrong plane, or getting lost in a new place, where your plans break down and you have to improvise a solution. As they told their stories a pattern emerged where in most cases the thing that led to the way out of whatever predicament was either approaching a stranger or a stranger noticing something was wrong and stepping in to help. In story after story, the issue was relatively quickly overcome with the help of someone the storyteller didn't know.

Working with the youth, we created a series of little amulets to capture ideas from these stories. The participants kept some of them to act as portable reminders that they were able to get themselves out of these unexpected situations and of the availability of human aid all around us. But they also embraced this idea of improvised connections with strangers and went into downtown Guelph to gift these amulets to passersby.

The youth also decided they wanted to carry brightly coloured balloons with them. I think they picked up on the notion that performance and spectacle grant permission to behave differently. It's important to be cognizant that the act of claiming public space isn't accessible to everyone in 
the same way; gender, culture, race, personal histories, etc., shape different relationships to being in public space. This is something I experience myself as an artist who often works in public settings. I see a lot of public art that acts in a very claiming way, which is a much more comfortable position for those who move very freely in public spaces. Not to digress too much, since a proper conversation about power and access in public work would require an entire article itself, but I think it very important that the ways in which public intervention can be strange and uncomfortable for many participants not be skipped over. Even within this group of participants I think it was clear that there were differing levels of comfort; and though it would be impossible to accurately pull out specific factors affecting this, it is nonetheless important to note. This is why I think the very simple gesture of having balloons was actually quite important. It was a gentle way of claiming presence and making a collective performative space that eased the initial trepidation and allowed these brief, non-commercial transactions to play out. Not unlike what happened with the Sudbury project, it gave the youth permission to engage the downtown in a different way.

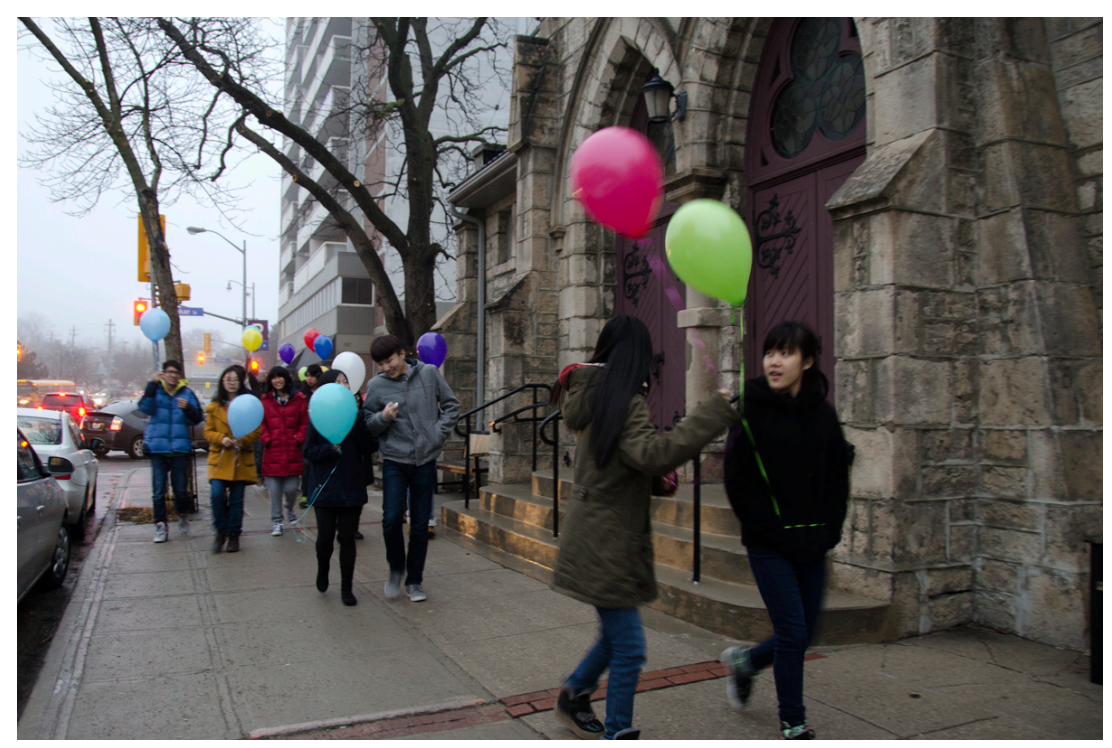

Figure 3: Stopgaps and Gems Parade (Photo: E. Jackson); Youth with balloons parade to Guelph's St. George's Square to share their stories and creations.

EJ: I would add that I think, and some said, that the intervention made them feel more at home, more like the city was theirs; and also more confident and at home with the English language. I also remember watching the teens approach a range of people they'd not otherwise have connected with including the man in the hot dog cart, who they approached with something to offer versus to ask for - a different, non-monetized exchange that he 
seemed very receptive to, surprised and happy about. And this turning outward was their own initiative. There was something really profound about the way something that started inside, in a closed and familiar group, ended up - through the participants' own choosing - with a very public, outdoor, interactive event. One thing I saw underlined by this project, and have seen in so many other contexts - improvised music comes to mind, given the work I do - is the incredible strength that can be found in accepting vulnerability. Not always, of course, and the stakes vary by context, but I have seen such powerful work come about when people are willing to acknowledge, confront, and then move within their vulnerability.

LH: Yes, similar to the SACY project, I think this acted as a probe that reveals possibilities that have always been there but rarely used.

EJ: And what do you see as the possible impacts, meaning, value of these moments? How might they function in a culture?

LH: I think in both cases it would be a big stretch to point to something and say this project changed that. Both of these projects were small and temporary by design. They act as probes of what is possible, or what might be possible, which also unsettle things a little, even if just momentarily and maybe that can make space for new ideas to come in or for old ones to be rearranged. I think there is a value in little gestures, ideally from different sources, that build up. To me this is more appealing than big bold moves.

In both projects, the uncertainty and discomfort of being in a public space in a strange way was very real and became an important part of the projects. I think at the very least this makes visible the limiting nature of normalized public behaviours. The ways we interact with each other can become very narrow (for what I think are mostly economic/political reasons but that's a whole other conversation), and so I think highlighting the contingent nature of these constraints is an important exercise. It is good practice to see what are the ways we don't interact with each other in public contexts but are available to us nonetheless. Speaking of exercise and practice, perhaps there is also value in moments where the range and scope of possible public relationships and exchanges are temporarily increased to push back against those limitations - you know, to keep the muscles limber!

\section{Acknowledgments}

We would like to thank our collaborator, Karen Kew, of Immigrant Services - Guelph Wellington, for her generous and creative work on Stopgaps and Gems, and for reviewing this piece before submission. Thanks, too, to the youth participants, who shared so generously of their insights, stories, and ideas. The dispatch grows from a presentation Jackson gave at McMaster 
University's Centre for Community Engaged Narrative Arts in March, 2106. Our conversation builds upon a presentation we gave at the 2015 Guelph Jazz Festival Colloquium, on the theme of Improvisation, Arts, and Well-being.

\section{References}

Estrada, A. (2013, July 10, 17:00). UCSB Black Studies scholar examines improvisation as a tool for social change. The Current: UC Santa Barbara. Retrieved from http://www.news.ucsb.edu/2013/013580/ucsb-black-studies-scholar-examinesimprovisation-tool-social-change 